\title{
The role of habitat configuration in shaping social structure: a gap in studies of animal social complexity
}

\author{
Peng He ${ }^{1,2}$ - Adriana A. Maldonado-Chaparro ${ }^{1,2}$ - Damien R. Farine ${ }^{1,2}$ (D
}

Received: 2 February 2018 / Revised: 1 June 2018 / Accepted: 12 November 2018 / Published online: 19 January 2019

(C) The Author(s) 2019

\begin{abstract}
Animal societies are shaped both by social processes and by the physical environment in which social interactions take place. While many studies take the observed patterns of inter-individual interactions as products and proxies of pure social processes, or as links between resource availability and social structure, the role of the physical configuration of habitat features in shaping the social system of group-living animals remains largely overlooked. We hypothesise that by shaping the decisions about when and where to move, physical features of the environment will impact which individuals more frequently encounter one another and in doing so the overall social structure and social organization of populations. We first discuss how the spatial arrangement of habitat components (i.e. habitat configuration) can shape animal movements using empirical cases in the literature. Then, we draw from the empirical literature to discuss how movement patterns of individuals mediate the patterns of social interactions and social organization and highlight the role of network-based approaches in identifying, evaluating and partitioning the effects of habitat configuration on animal social structure or organization. We illustrate the combination of these mechanisms using a simple simulation. Finally, we discuss the implications of habitat configuration in shaping the ecology and evolution of animal societies and offer a framework for future studies. We highlight future directions for studies in animal societies that are increasingly important in widely human-modified landscapes, in particular the implications of habitat-driven social structure in evolution.
\end{abstract}

\section{Significance statement}

There is now clear evidence that simple processes can generate apparent complex patterns of social structure. However, while studies such as those on collective behaviour and social networks have been focused on processes involving individual decisionmaking, broader patterns of social structure and social organization can also be shaped by factors that have more fundamental impacts on the movements of animals. One set of those factors is related to the amount and spatial arrangement of both biotic and abiotic components of the habitat in which animals live. Examples include the configuration formed by habitat patches connected through corridors, by the presence of hard boundaries between habitat types or by the uneven distribution of resources, mates and competitors across space. In this contribution, we highlight the potential effects of these, which are becoming increasingly important as studies start being able to track populations spanning larger landscapes.

\section{Communicated by P. M. Kappeler}

This article is a contribution to the Topical Collection Social complexity: patterns, processes, and evolution - Guest Editors: Peter Kappeler, Susanne Shultz, Tim Clutton-Brock, and Dieter Lukas

Electronic supplementary material The online version of this article (https://doi.org/10.1007/s00265-018-2602-7) contains supplementary material, which is available to authorized users.

Damien R. Farine

dfarine@orn.mpg.de

1 Department of Collective Behaviour, Max Planck Institute for Ornithology, Universitätsstraße 10, 78457 Konstanz, Germany
2 Chair of Biodiversity and Collective Behaviour, Department of Biology, University of Konstanz, Universitätsstraße 10, 78457 Konstanz, Germany 
Keywords Animal social networks $\cdot$ Habitat configuration $\cdot$ Movement decisions $\cdot$ Physical environment $\cdot$ Social organization $\cdot$ Social structure

\section{Introduction}

Animal societies are often described as exhibiting nonrandom interactions among socially connected individuals that form part of a complex social structure (Wittemyer et al. 2005; Sosa 2016). We know that social structure can have profound behavioural, ecological and evolutionary implications. For example, it can shape the physiology (Lurzel et al. 2010; Sachser et al. 2011), behaviour and morphology (Bölting and von Engelhardt 2017) of individuals; grouplevel processes such as information transmission (Allen et al. 2013; Aplin et al. 2015a), disease transmission (VanderWaal et al. 2014; Adelman et al. 2015) and mating systems (Oh and Badyaev 2010; Rezucha and Reichard 2014; MaldonadoChaparro et al. 2018); the direction and intensity of selection (McDonald and Pizzari 2018); and the ability and rates of evolutionary responses to selection (Montiglio et al. 2018b). Investigating the consequences of animal social structure lies in the heart of animal social ecology and evolution, as it relates social relationships among individuals, such as competition, cooperation and dominance (Whitehead 1997) and their fitness consequences (Silk et al. 2003, 2009; Ryder et al. 2008, 2009; Farine and Sheldon 2015; McDonald et al. 2017; Yang et al. 2017). However, understanding the underlying factors and mechanisms that determine how social structure is shaped remains challenging. Here, it has been helpful to consider interactions as resulting from the decision-making processes with respect to whom individuals choose to interact with (Hinde 1976; Whitehead 2008; Kurvers et al. 2014; Aureli and Schino 2019, topical collection on Social complexity). This approach can shed insights on relatively simple social decisions that could generate seemingly complex social structures (Couzin et al. 2005; Farine et al. 2017; Firth et al. 2017).

A pre-requisite for individuals to interact with others is that they need to be in relatively close physical proximity (Farine 2015), and for most animals, the social environment is first and foremost determined by their movement decisions (Emlen and Oring 1977; Farine et al. 2016; Bonnell et al. 2017). However, even if animals prioritise social cues over environmental features when making movement decisions (Strandburg-Peshkin et al. 2017), some features of the environment represent physical barriers while others facilitate movement, and therefore animal movements will, at least to some extent, be regulated by the physical environment. Take two songbirds whose home ranges are centred $100 \mathrm{~m}$ apart as an example. If these birds are separated by suitable habitat, then they are likely to encounter one another relatively frequently. By contrast, if they are separated by a highway, then they may never encounter one another, meaning that their 'apparent' distance is much larger than their physical distance. In this way, the physical features of the habitat through which animals move (e.g. the boundaries between a woodland and an agricultural land, or continental boundaries) will fundamentally shape the identity and rates of encounters among individuals, their patterns of social interactions (i.e. social structure) and social organization (i.e. the size, sexual composition and spatiotemporal cohesion of a society) (see detailed discussion of the two concepts in Kappeler and van Schaik 2002; Kappeler et al. 2013; Kappeler 2019, topical collection on Social complexity).

In addition to physically functioning as movement obstacles or 'highways', habitat components (e.g. resources, mates, predators, competitors, parasites or pathogens, which are usually unevenly distributed across space) can also affect where animals move by attracting or repelling them at specific locations. In such ways, these structural features can either gather or disperse individuals and thus increase or decrease the social encounters among individuals. Among those habitat components, resources play a fundamental and important role in shaping the spatial distribution (or space use) of animals (Getz 1961; Brown and Orians 1970; Clutton-Brock and Harvey 1977; Emlen and Oring 1977) and thus shape the patterns of inter-individual spatial proximity and potentially their social relationships (Mourier et al. 2012). For example, the amount and spatial arrangement of resources can determine the strength and patterns of inter-individual interactions (e.g. when resources are more spatially dispersed, interindividual interactions resulting from access to resources can be weakened; Petren and Case 1998). Moreover, the spatial distribution of resources can mediate the patterns of sexual interactions in territorial animals, especially in cases where the males' strategy is to access mates through gaining resources in their territories (i.e. resource defence polygyny tactic; Emlen and Oring 1977), which then shape the spatial distribution of females. Further, as limited resources can drive territoriality (via increasing levels of competition, Brown 1964) and territoriality can shape the ranging patterns of animals (Mitani and Rodman 1979), the amount of resources can affect how intense individuals interact with others even in territorial species. During breeding season, many animals build and hold territories to secure and protect resources. However, the non-breeding period is also key to understanding the social life of animals (Boucherie et al. 2019, topical collection on Social complexity), especially when the amount and spatial arrangement of resources are primary drivers of the ranging patterns of individuals. Predators within habitats can also play a role in shaping where and how prey individuals move, such as whether they are pressured into aggregating 
into shelters or directly choose to interact with others to avoid being predated (Herbert-Read et al. 2017). Notably, in natural environments, biotic and abiotic components are usually spatiotemporally dynamic, and this can drive temporal variation in the social relationships among individuals (e.g. the seasonal variation of social relationships in giraffes, Wolf et al. 2018).

Habitat structure is defined as the amount, composition and three-dimensional arrangements of both biotic and abiotic physical matters at a specific time and location in which an animal lives (see Bell et al. 1991; Byrne 2007). This concept captures three fundamental aspects of any given habitat: (1) the scale - the amount of spatial area, (2) the complexity - the relationship between the absolute amount of individual components of the physical matter and the scale and (3) the heterogeneity - the relative abundance of the different components at a given spatial scale (McCoy and Bell 1991). All these aspects of the habitat (or their combinations) can generate barriers to animal movement (e.g. roads; Rondinini and Doncaster 2002; Shepard et al. 2008) or can facilitate individual movement (e.g. corridors; Haddad 1999; Ibarra-Macias et al. 2011; Shepard et al. 2016). By facilitating or impeding the movements of animals, or attracting or repelling individuals, these structural features of habitat components will therefore mediate the ability or rate of contacts (or associations) among individuals as they move through the landscape.

However, researchers often interpret the observed patterns of social interactions as the products of purely social processes. Such an approach may be misleading or may lead to wrong conclusions. For example, habitat fragmentation can produce isolated subpopulations of animals that interact almost exclusively with others in their patch, resulting in seemingly distinct and consistent social communities over years (see example by Farine and Sheldon 2016), which could be misinterpreted as having some adaptive value (e.g. to prevent rapid diffusion of disease). However, the generative process responsible for global structure at the population level is predominantly abiotic (at least in the example given above). Thus, zooming out from very local interactions (e.g. at a smaller socio-spatial scale, such as social interactions in a chamber of an ant nest) to population-level structure (e.g. at a larger socio-spatial scale, such as social interactions of a population of songbirds in a forest) requires appropriate consideration of the physical environment in which interactions take place. The environment is well established as a major driver of broad (e.g. population and species levels) social tendencies (Mitchell et al. 1991; Sterck et al. 1997; Koenig 2002; Krause and Ruxton 2002). With improved technologies, researchers can now track and study social species at population scales, and this can help to uncover whether and to what extent habitat environments are responsible for patterns (or variations) we observe in social structure. Integrating concepts from movement ecology (how and where animals move) with social behaviour (who animals interact with and when) will strengthen our understanding of the generative processes underlying the structure of animal societies we study (Kays et al. 2015; Sih et al. 2018; Spiegel et al. 2018). In doing so, it will improve our ability to make predictions about how current and future modifications to habitat might shape the behaviours of organisms (Tucker et al. 2018).

In this paper, we focus on discussing how the amount and spatial arrangement of both biotic and abiotic components of habitat, defined here as habitat configuration, can shape the social structure (or the social organization) of group-living animals and its implications in ecological and evolutionary contexts. We first present the current understanding of the links between habitat configuration, animal movements and social structure (or social organization). Then, we propose that these links can be analytically integrated using network approaches and give an illustrative example to show the role of habitat configuration on animal social structure. Finally, we discuss the ecological and evolutionary implications of the effects of habitat configuration on animal social structure and propose a framework which outlines the role of habitat configuration on animal societies. Our paper provides important considerations and new research directions in studies of social complexity (see Kappeler 2019, topical collection on Social complexity) and, at the same time, new insights for the conservation of group-living animals in a changing world.

\section{Habitat configuration and animal movement}

Movements of animals across their habitats are important for processes such as finding new resources, acquiring mates (e.g. avoiding inbreeding) and reducing competition, all of which are linked to their survival and reproduction (Boinski and Garber 2000; Jonsen and Taylor 2000; Fahrig 2007; McLean et al. 2016). However, natural habitats are heterogeneous and habitat components (both biotic and abiotic, such as resources, shelters, mates) are rarely evenly distributed across space and often vary over time (i.e. they often exhibit spatial and temporal heterogeneity). Moreover, the same environment can be perceived and used differently across species, or even among individuals within species (e.g. due to individual differences in habitat familiarity), and these will also influence the way in which animals use the space (McIntyre and Wiens 1999). Thus, it is clear that animal movements are unlikely to be completely random or uniform in space and time. Instead, movement patterns often result from the interaction between animal movement behaviour and the characteristics of the environment in which the animals are embedded ( $\mathrm{McNab}$ 1963; Schick et al. 2008), which can have implications for the social relationships among individuals.

Ample evidence has shown that habitat configuration is a key determinant of the movement pattern of animals across a wide range of taxa and spatial scales. For example, at a smaller 
spatial scale, Crist et al. (1992) tracked the movements of three darkling beetle species (Eleodes spp.) in small plots that differ in vegetation cover and grazing intensities and found that the vegetation structure strongly affected darkling beetle movement pathways. Cartar and Real (1997) examined how resource dispersion influenced movements in a captive colony of bumble bees (Bombus occidentalis) and found that bees have lower directionality, higher frequencies of flower revisitation and greater flight distances among flowers in habitat with variable arrays of flowers compared to habitats with uniform arrays of flowers. Pinter-Wollman (2015) studied how the collective behaviour of harvester ants (Veromessor andrei) is affected by the spatial constraints of the architecture of nests on individual movement. By quantifying the connectivity among chambers of the nests using network approaches and measuring the speed of ants (collectively) recruiting to food (pieces of apple, which were experimentally placed $10-15 \mathrm{~cm}$ from the nest entrances), they found that the speed at which ants recruit food increases with chamber connectivity. This study indicates that the habitat configuration (in this case nest architecture) can influence where individuals can move and how they interact with each other, and therefore, how their collective behaviours (which emerge from such patterns of social interaction) are shaped. However, as recently highlighted by Pinter-Wollman et al. (2017), the role of the configuration of the space in which animals can move, such as the architecture of nests, in shaping collective behaviours is rarely considered.

Studies have also found effects of habitat configuration on movement across broader spatial scales. Coulon et al. (2008) found that presence and arrangement of buildings, roads and valley bottoms significantly affected the ranging behaviour of roe deer (Capreolus capreolus) in southwestern France. In a similar study, Kie et al. (2005) found that the topographic features of the habitat, in particular major drainages on ridge tops and in valley bottoms, shaped the movement direction of North American elk (Cervus elaphus). Using high-resolution GPS, McLean et al. (2016) tracked arboreal white-faced capuchin monkeys (Cebus capucinus), mantled howler monkeys (Alouatta palliata) and black-handed spider monkey (Ateles geoffroyi) in a tropical moist forest on Barro Colorado Island, Panama. Using high-resolution airborne LiDAR (light detection and ranging) data to map the 3-D structural properties of the forest canopy of the whole island, they could relate the movement patterns of the three primate species to canopy attributes. They found that all these three species avoided canopy gaps (which function as physical obstacles for lateral movement of these species). An experimental study by Mansergh and Scotts (1989) showed that increasing the connectivity between bisected breeding habitat patches of mountain pygmy-possum (Burramys parvus), by constructing corridors and tunnels, facilitated the movements of males between habitat patches, an essential aspect in the social organization (the sexual composition) of this species. More recently, by combining simultaneous high-resolution GPS tracking of olive baboons (Papio anubis) and 3-D habitat reconstructions from a drone, Strandburg-Peshkin et al. (2017) quantified the relative contribution of habitats on movements. They found that the baboon troop they studied had a strong preference for following roads when moving towards or away from their sleep site and general avoidance of areas with dense vegetation. Particularly, their study highlights the important roles that the spatial arrangement of habitat components plays in shaping not just individual-level movement patterns but also collective animal movement as a group. Together, these examples demonstrate that habitat configuration across entire landscapes (such as resource abundance and spatial distribution, as well as topographic features of the habitat) affects individual movement decisions of animals, and more generally their movement patterns, which have implications in shaping the patterns of inter-individual social contacts or associations.

At an even larger spatial scale (e.g. continental scale), animal movement can also be affected by structural features of the habitat. For example, during bird migrations, the spatial arrangement of suitable habitats (usually referred to as stopover sites) and barriers (e.g. open water, deserts, mountains) between wintering and breeding grounds can shape the migratory routes of migrants. For instance, white storks (Ciconia ciconia) that breed in Europe travel eastwards or westwards in order to avoid crossing the Mediterranean sea and the Sahara desert during southward migration and thus migrate to Africa via the Middle East or over the strait of Gibraltar (Cramp and Simmons 1977; Leshem and Yom-Tov 1998; Berthold et al. 2001; Flack et al. 2016) (Fig. 1). In this case, the Mediterranean Sea, a continental feature that acts as a landscape barrier, is likely to increase the encounters among individuals at bottlenecks and in their approach as flocks converge in a funnel-like fashion. Thus, the spatial configuration of the continents over which animals migrate can generate patterns of correlations between the movement and social behaviour among individuals. As some birds learn how to migrate from others (Mueller et al. 2013; Kao et al. 2018), the spatial arrangement of the migratory stopover sites could potentially shape social learning processes of migration. For example, at converging stopover sites (e.g. the strait of Gibraltar which is intensively used by white storks during migration), juveniles could have more choices on whom to interact with and learn from. Highdensity aggregations could result in individuals learning different routes for different stages of migration and therefore underlie diversity in observed migration pathways over the entire route. Increased rates of interactions with others could also have repercussions for other population processes, such as mate choice or disease transmission. 
Fig. 1 The southward migratory routes of juvenile white storks (Ciconia ciconia) that bred in Europe (Greece, Russia, Poland, SW Germany and Spain). In this example, the Mediterranean Sea and the Sahara Desert impede the migration of white stork populations, while the Iberian Peninsula, the land that links in the Middle East, and the Nile facilitate their migration. Each line colour in the map represents one individual; the yellow-to-red colour highlights mark areas of particularly high intensity of GPS points, with red capturing the highest densities. High resolution GPS locations are from

Movebank data repository 'MPIO white stork lifetime tracking data (2013-2014)' (doi:https://doi.org/ $10.5441 / 001 / 1.78152 \mathrm{p} 3 \mathrm{q})$ by

Flack et al. (2016) and map data from R package 'mapdata' (Brownrigg et al. 2018)

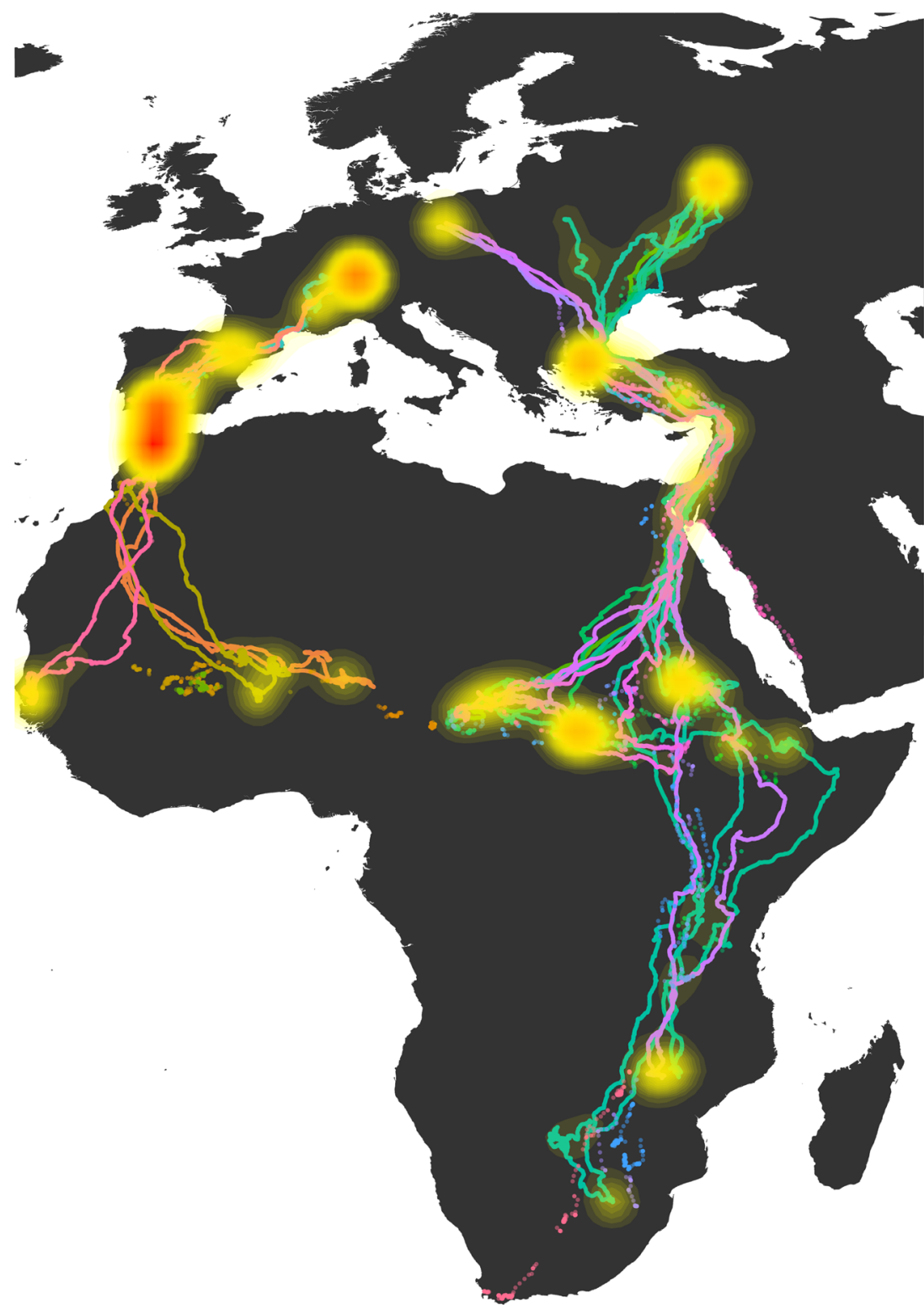

\section{Habitat configuration and social structure}

Empirical studies have demonstrated links between physical features of habitat and social structure. For example, Webster et al. (2013) experimentally compared foraging schools of sticklebacks (Gasterosteus aculeatus) in open habitats versus habitats where black plastics as barriers were imposed. They found that the imposed barriers significantly affected the social network structure of fish, in that individuals in open environments interacted with each other more equally than individuals in environments where barriers were imposed. As a result, the environment also influenced the pattern of social information transmission through its effects on the pattern of the shoals' association network structures. In a similar study, Leu et al. (2016) experimentally manipulated the spatial structure of natural habitats by adding short fences across the landscape while synchronously capturing the movements of sleepy lizards (Tiliqua rugosa) using GPS trackers. They found that the social connectivity (network density) and social stability were higher in populations in the experimentally modified habitat compared to those of the population in unmanipulated environments. They argued that structural complexity (as induced by adding fences) of habitat increased social connectivity among individuals by funneling their movements along the same physical space. In another study, Lattanzio and Miles (2014) looked at the consequences of habitat disturbance (in terms of burn frequency) on the social dynamics of male tree lizards (Urosaurus ornatus). They showed that at the site where trees were frequently burnt (which increased levels of fragmentation of habitats), the 
spatial network of individuals shifted towards closer neighbour associations (i.e. increasing the density and presumably the rates of social interactions). Together, these studies clearly show that habitat components that influence where individuals move, in particular barriers, directly impact the rates at which individuals encounter others.

Several recent studies have quantified the effects of changing availability and configuration of habitat components on population-level social structure, providing (natural and controlled) experimental evidence for mechanistic links between these. Lantz and Karubian (2017) investigated the social connectivity of red-backed fairy-wren (Malurus melanocephalus) before and after wild fires (during which the number and spatial arrangements of habitat patches changed). They found that the density of network ties was higher among individuals whose habitats were affected by wild fires than among those whose habitats were not affected by fire and suggest that this was caused by a reduction in the available area for affected individuals to live (increasing the density of individuals in the available habitat). A study of mixed species bird flocks by Mokross et al. (2014) examined how large-scale habitat alteration influenced the patterns of social interactions and social organization among Amazonian bird flocks at both the species and flock levels. They found that habitat type (i.e. primary forest, different levels of fragmented forests and secondary forests) had notable effects on the social structures at both the species and flock levels. The frequency of (non-trophic) associations among species decreased when the level of habitat fragmentation increased, and at the flock level, the presence of higher forest canopy increased flock cohesion and stability (flock-level social organization). Finally, Firth et al. (2016) individually marked a community of great tits (Parus major), blue tits (Cyanistes caeruleus), marsh tits (Poecile palustris), coal tits (Periparus ater) and Eurasian nuthatches (Sitta europaea) using passive integrated transponder (PIT) tags, the ID of which could be read by automated readers installed at artificial feeders. Then, using selective feeders (which were programmed to control individuals' accesses to the food in the feeders), they manipulated foraging range of individuals by socially splitting them into two spatially overlapping subcommunities. Using presence-absence data collected by readers at those fixed feeders, they measured the social structure of the community before and after the manipulation and found that the resulting social network structure better predicted the transfer of experimentally seeded information than did the pre-treatment social network. Their study provides important experimental evidence for a functional link between habitat configuration (in that case resource distribution and availability) and population-level social processes (e.g. information spread). Together, these examples show clearly how the spatial arrangement of habitat components can influence social dynamics.
Few studies have investigated the direct link between animal movement and population-level patterns of social interactions. To our knowledge, the best examples come from the fish literature. Many fish populations exhibit strong phenotypic assortment - individuals are typically found in shoals containing similarly sized fish. In extreme cases, because fish have a large range of body sizes in their lifetimes, some fish are more likely to be found in shoals containing similarly sized heterospecifics than in shoals containing differently sized conspecifics (see review in Hoare et al. 2000; Krause et al. 2000). While such a process could be driven by complex social preferences, evidence suggests that the underlying mechanisms are relatively simple. For example, because swimming speed is correlated to body size, a mixed size shoal will rapidly become assorted by body size as larger (and faster) individuals move towards the front and smaller (and slower) individuals are left behind (Jolles et al. 2017). An alternative mechanism is size-based differences in habitat preferences (Macpherson and Duarte 1991; Manderson et al. 2004). Smaller fish are more prone to predation (even by conspecifics) and therefore prefer the cover provided in shallower water. By contrast, larger fish either cannot access this habitat or prefer the more profitable pelagic zone. Body size assortment could therefore also be a result of differences in habitat suitability, rather than social preferences per se, and within-species variation in habitat suitability could be a worthwhile topic for future investigations.

\section{Networks as a unifying tool linking habitat configuration, animal movement and social structure}

Networks are becoming widely used to study structural properties of interconnected systems (Pilosof et al. 2017; Montiglio et al. 2018a). For example, in the study of animal social behaviour, networks can be constructured where nodes represent individuals and edges represent the associations or interactions between them (Whitehead 2008; Farine and Whitehead 2015; Krause et al. 2015; Wilkinson et al. 2019, topical collection on Social complexity). The social structure of a given population can be measured using network metrics such as community structure (the presence of strongly connected clusters of individuals that interact more among themselves than they do with others, Shizuka and Farine 2016) and phenotypic assortativity (the propensity for individuals to interact with others that are more phenotypically similar to them, Croft et al. 2005; Farine 2014). For example, a tiny islet (the wide part of which is ca. $250 \mathrm{~m}$ ) in the Galápagos archipelago hosts ca. 1000 Galápagos sea lion (Zalophus wollebaeki), where the land area available for breeding and resting varies with the temporal tidal levels. With limited space, individuals are spatially bound (individuals shows fine-scale site fidelity, in that they tend to use the 
area they used more often), and such pattern of habitat use by individuals explained the community-level structure in a social network (Wolf et al. 2007) and was thought to produce genetic assortment at the level of the population (see Wolf and Trillmich 2008).

Network approaches have also been developed to help quantify the features of habitat configuration. For example, network metrics have been frequently employed to quantify the spatial heterogeneity, spatial structure and connectivity of habitat patches across or within species' ranges in landscape ecology (Cantwell and Forman 1993; Fortin et al. 2012). A number of studies have used these networks to explore the consequences of connectivity across landscapes on population- and communitylevel processes (see examples in the review by Grant et al. 2007). At smaller spatial scales, network analysis contains useful tools to characterise and quantify local patterns of connectivity. For example, the architecture of nests can be represented as a network of corridors connecting chambers and have been used in studies of social and collective behaviours in social insects (Buhl et al. 2004; Pinter-Wollman 2015). With such an approach, researchers are able to build explicit network models to quantitatively capture the structural properties of habitats in complex, static or dynamic environments.

Meanwhile, the application of network tools for studying the movement patterns of animals in movement ecology has become increasing popular thanks to our improved ability in collecting animal movement data across larger numbers of individuals (Bonter and Bridge 2011; Jacoby and Freeman 2016). For example, telemetry data (presence-absence data collected by recorders in fixed locations) have been used to construct movement networks of small-spotted catshark (Scyliorhinus canicula) and Caribbean reef shark (Carcharhinus perezi) (Jacoby et al. 2012), white-striped free-tail bats (Tadarida australis) (Rhodes et al. 2006) and bumblebees (Bombus terrestris) and honey bees (Apis mellifera) (Pasquaretta et al. 2017). Network tools are well suited for studying movements and the inter-individual relationships of social animals as they allow integration of movement data in the same analytical framework as used for quantifying social interaction data. Simultaneously capturing habitat data, social data and movement data across many individuals at once facilitate partitioning and quantifying the relative effects of physical environments on the patterns of social interactions from purely social processes (see Aplin et al. 2015b; Farine et al. 2015; Radersma et al. 2017).

\section{Exploring the link between habitat connectivity and social network structure}

To better illustrate the links between habitat configuration and animal social structure and organization, we simulate how habitat connectivity can shape the movement patterns of individuals and explore how habitat connectivity can shape global structure of animal populations. We create a simple simulation in which we randomly allocated 20 individuals into 4 habitat patches that vary in the connectivity among them (see Fig. $2 \mathrm{a}-$ d). Difference in connectivity can be due, for example, to differences in corridor width or openness of the connecting area (i.e. matrix). In each simulation step, individuals have a 0.99 probability of staying at their current patch, while the remaining 0.01 units of probability are equally allocated to moving to another connected patch. If there are no connections to the current patch, the probability of an individual remaining on that patch is always 1 . For each habitat scenario, we simulate 100 opportunities per individual to make between-patch movements and generated a weighted social network, where the weights of edges are based on the proportions of steps in which each pair of individuals co-occur at the same patch. We then investigate the effects of habitat configuration on social structure by calculating four network-level metrics: (1) mean network density, (2) mean non-zero edge weight, (3) mean network assortativity in terms of the ID of the patch in which individuals are initiated (calculated using the R package 'assortnet'; Farine 2014) and (4) mean network modularity (calculated with R package 'igraph'; Csardi and Nepusz 2006). We find that when habitat patches are well connected, network density is highest but assortativity and modularity are low (e.g. Fig. 2a, b). By contrast, as soon as patches become disconnected, network density becomes low, but average edge weight, assortativity and modularity increase (see Fig. 2c, d). In larger landscapes (containing 40 individuals in 8 patches in this case, as shown in Fig. 2e), all measures are lower, but the relative values of density, edge weights and assortment are more similar to landscapes with disconnected patches (Fig. 2c, d) than to smaller landscapes with fully connected patches (Fig. 2a, b), thus highlighting the important effects of scale in the analysis of animal social structure.

Our simulation highlights the role of habitat configuration in shaping the social structure of group-living animals. It, together with the empirical literature we have surveyed, suggests that future empirical researches on fine-scale animal social behaviour should also pay close attention to environmental factors such as habitat configuration. Further, the patterns can vary according to the size of the landscapes, with larger landscapes appearing to act as being more disconnected. Given that the movement abilities can vary significantly among species (or even among individuals within a population), the degree to which the configuration of habitats can shape the movements of animals will vary (e.g. the features that shape the movements of, for example, arthropods, is less likely to affect the movements of larger terrestrial or aerial animals). Thus, integrating the scale at which animal movement is affected by the environmental factors can help us to accurately interpret potential changes in the social structure and social organization. 


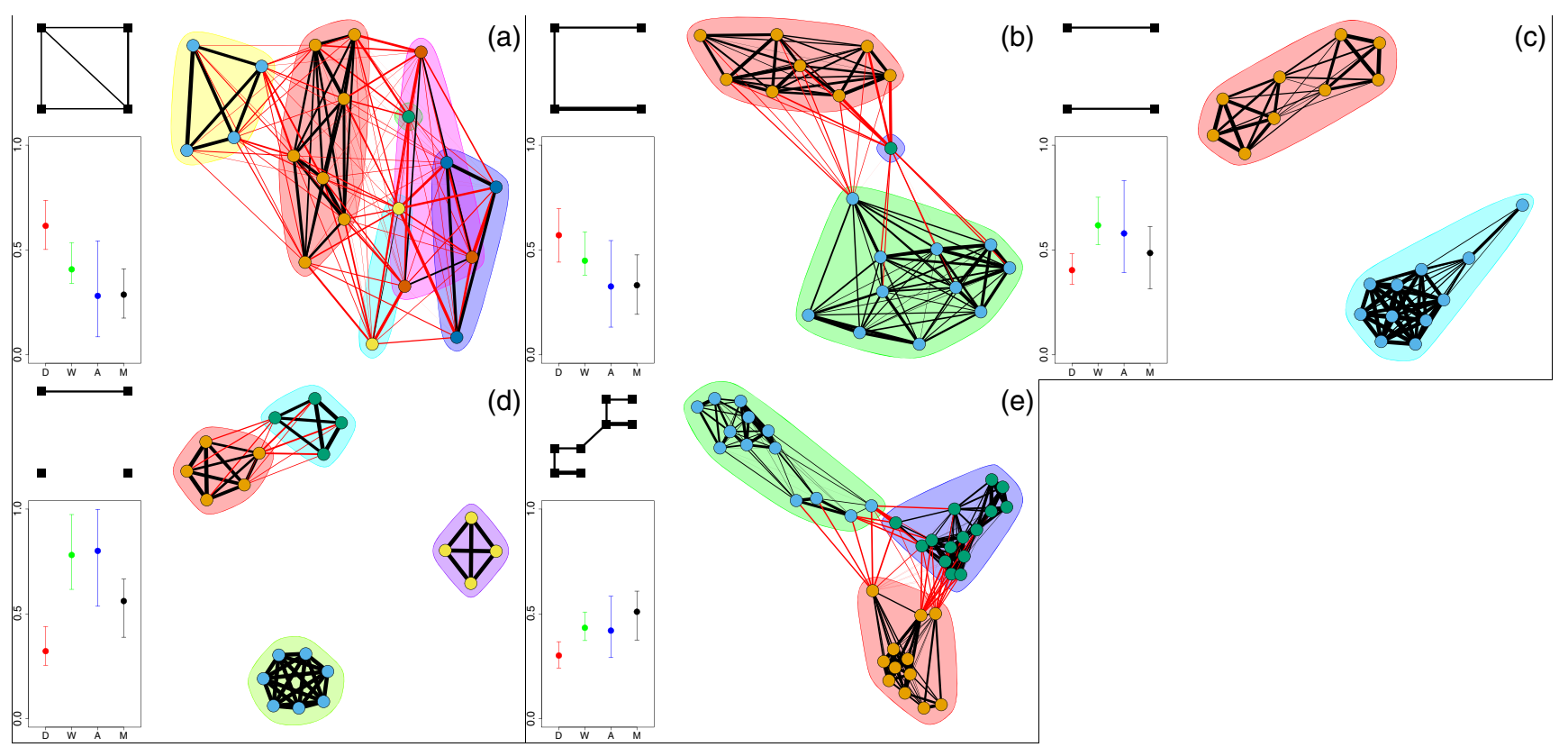

Fig. 2 A simple illustration of how habitat connectivity can shape the overall patterns of social interactions among individuals. Individuals are represented with circles (nodes in the networks) in the main panels, while habitat patches are shown as black squares in the top-left insets; the probabilities of moving from one patch to the other connected patch are shown as weighted segments between black squares in the top-left insets. In the social networks, edges (lines between pairs of nodes) are based on the proportions of timesteps in which each pair of individuals co-occur at

\section{Ecological and evolutionary implications of habitat-structured social systems}

We argue that animal movement networks that bridge habitat with social networks will yield significant mechanistic insights into many seemingly complex patterns of social behaviours that have been observed across the animal kingdom. Individuals have been shown to make social decisions with apparent knowledge (consciousness) of future consequences (Cheney and Seyfarth 1999). Yet, it is also widely acknowledged that simple mechanical movement rules (as demonstrated by numerous studies of collective animal behaviour) can generate a range of higher-level properties, from emergent leadership (Couzin et al. 2005), to repeatable differences in individual spatial (Farine et al. 2017) and social positions (Jacoby et al. 2014; Aplin et al. 2015b; Firth et al. 2017). Thus, simple mechanically generative processes that arise from the physical habitat environment should also be taken into account when behavioural, ecological and evolutionary questions of social animal groups are discussed.

Why should we care about the link between habitat configuration and social structure? We suggest that doing so could yield new insights on the ecology and evolution in natural populations. From a behavioural and ecological perspective, changes in the social structure have impacts on processes such as mate choice, antipredator responses and disease and information transmission. For example, habitat configuration could underpin divergence in the same patch. Highlight colours (and node colours) represent communities detected in the network, with red lines denoting the betweencommunity edges and black lines denoting within-community edges. The bottom-left insets show the network statics and 95\% confidence intervals (D: mean network density with $95 \% \mathrm{CI}$; W: mean non-zero edge weight with $95 \% \mathrm{CI}$; A: mean network assortativity with $95 \% \mathrm{CI}$; M: mean network modularity with $95 \% \mathrm{CI}$ )

behaviours among populations. Many songbirds show local variation in bird song (Fayet et al. 2014), with potential implications for evolution via reproductive isolation (Slabbekoorn and Smith 2002), while behavioural variants can rapidly become established and then maintained in different parts of seemingly contiguous populations (Aplin et al. 2015a). Habitat configuration can shape the behaviours of animals (Gill and Wolf 1975; DonaldsonMatasci and Dornhaus 2012), and local spatial variation in the habitat components and conditions in which individuals are raised can also impact the behaviours they exhibit later in life (Boogert et al. 2014; Slagsvold and Wiebe 2018), meaning that factors such as habitat heterogeneity could influence the behavioural heterogeneity in social groups. Finally, the phenotypes with whom individuals interact with has been shown to impact selection on a range of traits, including morphology (Formica et al. 2011) and dispersal behaviour (Farine and Sheldon 2015).

When populations become phenotypically structured, there is the potential for local differences in the social environments that individuals experience to impact the strength and direction of selection. For example, when groups of interacting individuals are small, there is an inevitable negative covariance between the trait value of an individual and the mean of the trait value of those that it interacts with (McDonald et al. 2017). Thus, if the environment reduces the pool of available individuals to interact with, it can also increase the strength of social selection. By influencing the number and rates of interactions, the physical structural 
features of habitats can also impact rates of evolutionary responses to selection. A recent study by Montiglio et al. (2018b) suggested that intermediate population interaction densities generate the strongest rates of phenotypic change in social traits. Intermediate densities of interactions also generate the largest variation in phenotypic changes among groups or populations, meaning that different groups or populations could end up on different evolutionary trajectories, potentially amplifying within-species variation. If habitat configuration also limits dispersal, thereby producing population-level genetic assortativity, this could further enhance the rates of evolution by creating a genetic or phenotypic covariance among individuals. Thus, limited movement combined with local variation in habitat could intensify local differences in selection (Garant et al. 2005).

Finally, an interesting question is how organisms might themselves shape or reinforce habitat structural features that underpin social structure. Many species act as dispersal agents for seeds or play a major role in pollinating plants. Such contributions to their ecosystem could generate feedback mechanisms, or co-evolutionary dynamics, across species. For example, a restricted movement corridor may receive a disproportionate number of seeds that are preferred by a species, which in turn could promote movement through that habitat. Should the habitat around that corridor eventually become more suitable for movement, the original corridor could still remain a preferred pathway as a result of the earlier dispersal of seed through that area (and therefore the presence of preferred tree species), meaning that effects of habitat geometry could be maintained over long periods of time. Such patterns could easily be (mis)interpreted as being cultural.

\section{Framework outlining the role of habitat configuration on animal socialites}

Habitat configuration can shape the movements of individuals within a population. Studies from movement ecology have widely explored links between habitats and properties of individual behaviour (Jacoby and Freeman 2016), such as movement distances (Tucker et al. 2018), habitat use (Dahl and Greenberg 1996), dispersal (see Vasudev et al. 2015) and migration (Flack et al. 2016). Thus, the amount and arrangement of both the biotic and abiotic components of the habitat can either increase or decrease rates of movement across different parts of the landscape. By shaping individual movement behaviour and patterns of social encounters, we have argued that habitat configuration can have fundamental impacts on subsequent social behaviour and emergent social structure (Fig. 3). For example, using a simulation model, Spiegel et al. (2017) suggested that the social structure of a simulated population emerged from the interaction between the movement strategy of agents and the pattern of resource distribution. In their model, agents in areas with clumped resources had fewer encounters and formed less dense social networks compared to those in areas with more spread resources.

Patterns of social interactions give rise to the social organization of the population, such as social structure, mating patterns and kinship structure, and social organization is inherently linked to population or community dynamics (Kappeler and van Schaik 2002; Kappeler et al. 2013). The density of social connections and the structure of connections among kin are well known to influence demographic parameters (Silk et al. 2003, 2009; Formica et al. 2012; Yang et al. 2017). Further, the structure of populations is hypothesised to impact population processes, including disease (Chen et al. 2014; VanderWaal et al. 2014; Silk et al. 2017a, 2017b) and information (Aplin et al. 2015a; Firth et al. 2016; Jones et al. 2017) transmission and the ability for social traits to evolve (Montiglio et al. 2018b). In particular, more clustering, or strong shared connections among individuals, is generally thought to reduce rates of disease transmission among populations (Eames 2008). Thus, habitats with more isolated patches are likely to generate more clustered social networks and have low rates of disease or information transmission at the population level. Such relationships also have a feedback effect on the processes that generate them (grey arrows, Fig. 3), meaning that the population-level structure can ultimately affect individual movement phenotypes

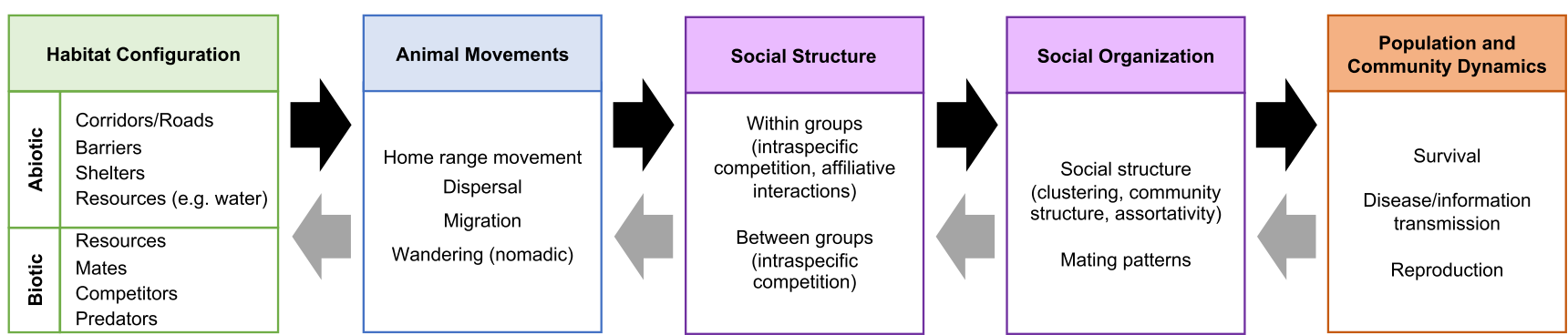

Fig. 3 A conceptual framework to illustrate the relationship between habitat configuration, animal movement, social behaviour and demography. Changes in the amount and spatial arrangement of both abiotic and biotic components of habitats can affect patterns of movements at different spatial scales such as habitat use, dispersal and migration, which in turn can facilitate or restrict the social interactions among individuals within and between groups thus influencing key aspects of sociality such as the social structure and the mating patterns. These effects can have potential ecological and evolutionary consequences 
Table 1 Predictions and hypotheses concerning how the biotic and abiotic components of the habitat can shape animal movement, their social relationships with others and the signature of these effects on social network structure

\begin{tabular}{|c|c|c|c|c|}
\hline Expected effects on mov & vement & Components & Expected effect on social interactions & Expected effects on social network structure \\
\hline \multirow[t]{4}{*}{$\begin{array}{l}\text { Behaviourally shaping } \\
\text { movement decisions } \\
\text { (why and when to } \\
\text { move) }\end{array}$} & Attract & Resources & $\begin{array}{l}\text { Higher rates of repeated social interactions } \\
\text { where (or when) resources are more } \\
\text { clustered }\end{array}$ & $\begin{array}{l}\text { More defined network communities and } \\
\text { higher modularity when resources are } \\
\text { more clustered resulting in higher mean } \\
\text { association strength and density within } \\
\text { communities }\end{array}$ \\
\hline & & Mates & $\begin{array}{l}\text { Fewer mates trigger more agonistic } \\
\text { interactions among males (or females) }\end{array}$ & $\begin{array}{l}\text { Stronger edge weight in male-male } \\
\text { (or female-female) interaction networks } \\
\text { and higher density in sexual networks }\end{array}$ \\
\hline & Repel & Competitors & $\begin{array}{l}\text { Higher levels of competition generate more } \\
\text { agonistic interactions among individuals }\end{array}$ & $\begin{array}{l}\text { Stronger edge weight in directed agonistic } \\
\text { interaction networks }\end{array}$ \\
\hline & & Predators & $\begin{array}{l}\text { Greater predation pressure often increases } \\
\text { group size }\end{array}$ & Higher mean degree in riskier habitats \\
\hline \multirow[t]{2}{*}{$\begin{array}{l}\text { Physically shaping } \\
\text { movements (how } \\
\text { and where to move) }\end{array}$} & Facilitate & $\begin{array}{l}\text { Corridors } \\
\text { Roads }\end{array}$ & $\begin{array}{l}\text { Presence of preferred movement paths } \\
\text { (habitat corridors, animal tracks, roads) } \\
\text { increase frequency of encounters } \\
\text { among individuals }\end{array}$ & $\begin{array}{l}\text { Increase network density and greater } \\
\text { assortative mixing }\end{array}$ \\
\hline & Impede & $\begin{array}{l}\text { Barriers (e.g. } \\
\text { fences, roads) } \\
\text { Habitat transformation }\end{array}$ & $\begin{array}{l}\text { Reduced frequency of social encounters by } \\
\text { individuals restricted to different patches } \\
\text { and greater rates of social encounters } \\
\text { among individuals in the same patch }\end{array}$ & $\begin{array}{l}\text { Increased network clustering and } \\
\text { community structure, resulting in } \\
\text { higher modularity }\end{array}$ \\
\hline
\end{tabular}

(movement phenotype can also feedback onto the environment) and drive adaptation to local environmental conditions.

Our proposed framework can be used to categorise the sources of the effects that arising from the amount and spatial arrangement of habitat components. It can be employed to generate a range of predictions or specific hypotheses on how structural features of habitat environments can affect different aspects (i.e. movement decisions, the outcomes of movement decisions), as well as the types of movements animals are doing (i.e. home range movement, dispersal, migration, wandering), and thus also the quality of social relationships (Table 1). Furthermore, the framework can be used in the context of conservation biology to evaluate the impact of threats such as habitat loss or fragmentation across a range of species that exhibit different types of social behaviour (from territorial individuals through to stable groups).

\section{Conclusions}

Animal societies are often viewed as complex systems in which inter-individual interactions are ubiquitous and their consequences at the population level are unpredictable. Many studies suggest that non-random structural features of social networks, such as multi-level or hierarchical structures or phenotypic assortativity, represent the outcome of complex behaviours. However, many passive processes or simple mechanisms can also impose non- random patterns in social structure (Cantor et al. 2012; Mourier et al. 2012; Firth et al. 2017; Cantor and Farine 2018), which can strongly affect a range of population-level processes spanning both ecology and evolution. Environmental factors (e.g. the structure or configuration of habitat patches) can regulate the patterns of social interactions by affecting the rates at which such interactions take place and who is present, with consequences for the social environments that individuals experience.

We propose that the effects of these environmental aspects on animal social patterns, processes and evolution should be more widely considered. This can easily be achieved by explicitly accounting for, or removing the effects of space in animal social network data analysis, and recent studies in the literature have proposed methods. For example, we can quantify the relative contributions of social behaviour and habitat configuration to social complexity by using permutation tests for network hypothesis (Croft et al. 2011; Farine 2017), generalised affiliation indices for extracting affiliations from network data (Whitehead and James 2015), randomisation of animal movement paths for teasing apart the underlying spatial constrains on the patterns of social interactions among individuals (Spiegel et al. 2016) or recently proposed methods to quantify complexity in animal populations (see Weiss et al. 2019, topical collection on Social complexity), which can easily be compared to spatially explicit null models (see Farine 2017) to quantify the effects of habitat configuration on animal social complexity (see also Aplin et al. 
2015b). However, we suggest that the generative processes that underpin population-level network structure of animals are still relatively unknown. Ultimately, this is where any selection processes arising from the social environment should drive an evolutionary response (i.e. in how individuals make decisions). While growing volume of ecological data can be collected thanks to recent advances in technologies, and many complex patterns and processes in ecology and evolution can be depicted and analysed using network models (Proulx et al. 2005; Dale and Fortin 2010), we suggest that future studies in animal social ecology and evolution can investigate how environmental factors drive complexity in animal societies and social processes by integrated analyses of different types, layers or organizations of networks (Kivelä et al. 2014; Montiglio et al. 2018a). Moreover, because social behaviour can respond to changes in habitat configuration, the relationship between social structure, animal movement and habitat configuration has important implications for conservation. Understanding how habitat changes, for example as a result of habitat loss, harder borders between agricultural and conservation areas and higher density in urban landscapes, can affect animal movement should also be carefully considered in the conservation of social species.

Acknowledgments Open access funding provided by Max Planck Society. We thank Dr. Peter Kappeler for inviting us to participate in this topical collection on social complexity, and Dr. Orr Spiegel, Dr. Dieter Lukas, Dr. Peter Kappeler and three anonymous reviewers for their constructive comments on our manuscript.

Funding information This study was funded by the Max Planck Society and a DFG grant (FA 1420/4-1) awarded to DRF. PH received extra funding from the China Scholarship Council (No. 201706100183).

\section{Compliance with ethical standards}

Conflict of interest The authors declare that they have no conflict of interest.

Open Access This article is distributed under the terms of the Creative Commons Attribution 4.0 International License (http:// creativecommons.org/licenses/by/4.0/), which permits unrestricted use, distribution, and reproduction in any medium, provided you give appropriate credit to the original author(s) and the source, provide a link to the Creative Commons license, and indicate if changes were made.

Publisher's Note Springer Nature remains neutral with regard to jurisdictional claims in published maps and institutional affiliations.

\section{References}

Adelman JS, Moyers SC, Farine DR, Hawley DM (2015) Feeder use predicts both acquisition and transmission of a contagious pathogen in a North American songbird. Proc R Soc B 282:20151429

Allen J, Weinrich M, Hoppitt W, Rendell L (2013) Network-based diffusion analysis reveals cultural transmission of lobtail feeding in humpback whales. Science 340:485-488
Aplin LM, Farine DR, Morand-Ferron J, Cockburn A, Thornton A, Sheldon BC (2015a) Experimentally induced innovations lead to persistent culture via conformity in wild birds. Nature 518:538-541

Aplin LM, Firth JA, Farine DR et al (2015b) Consistent individual differences in the social phenotypes of wild great tits, Parus major. Anim Behav 108:117-127

Aureli F, Schino G (2019) Social complexity from within: how individuals experience the structure and organization of their groups. Behav Ecol Sociobiol, https://doi.org/10.1007/s00265-018-2604-5 this issue

Bell SS, McCoy ED, Mushinsky HR (1991) Habitat structure: the physical arrangement of objects in space. Chapman and Hall, Dordrecht

Berthold P, van den Bossche W, Fiedler W, Kaatz C, Kaatz M, Leshem Y, Nowak E, Querner U (2001) Detection of a new important staging and wintering area of the white stork Ciconia ciconia by satellite tracking. Ibis 143:450-455

Boinski S, Garber PA (eds) (2000) On the move: how and why animals travel in groups. University of Chicago Press, Chicago

Bölting S, von Engelhardt N (2017) Effects of the social environment during adolescence on the development of social behaviour, hormones and morphology in male zebra finches (Taeniopygia guttata). Front Zool 14(5)

Bonnell TR, Clarke PM, Henzi SP, Barrett L (2017) Individual-level movement bias leads to the formation of higher-order social structure in a mobile group of baboons. Roy Soc Open Sci 4:170148

Bonter DN, Bridge ES (2011) Applications of radio frequency identification (RFID) in ornithological research: a review. J Field Ornithol 82:1-10

Boogert NJ, Farine DR, Spencer KA (2014) Developmental stress predicts social network position. Biol Lett 10:20140561

Boucherie HP, Loretto MC, Massen JMJ, Bugnyar T (2019) What constitutes 'social complexity' and 'social intelligence' in birds? Lessons from ravens. Behav Ecol Sociobiol, https://doi.org/10. $1007 / \mathrm{s} 00265-018-2607-2$ this issue

Brown JL (1964) The evolution of diversity in avian territorial systems. Wilson J Ornithol 76:160-169

Brown JL, Orians GH (1970) Spacing patterns in mobile animals. Annu Rev Ecol Evol Syst 1:239-262

Brownrigg R, Minka TP, Becker RA, Wilks AR (2018) Mapdata: extra map databases, https://cran.r-project.org/web/packages/mapdata/ mapdata.pdf. Accessed 20 May 2018

Buhl J, Gautrais J, Sole RV, Kuntz P, Valverde S, Deneubourg JL, Theraulaz G (2004) Efficiency and robustness in ant networks of galleries. Eur Phys J B 42:123-129

Byrne LB (2007) Habitat structure: a fundamental concept and framework for urban soil ecology. Urban Ecosyst 10:255-274

Cantor M, Farine DR (2018) Simple foraging rules in competitive environments can generate socially structured populations. Ecol Evol 8: 4978-4991

Cantor M, Wedekin LL, Guimaraes PR, Daura-Jorge FG, Rossi-Santos MR, Simoes-Lopes PC (2012) Disentangling social networks from spatiotemporal dynamics: the temporal structure of a dolphin society. Anim Behav 84:641-651

Cantwell MD, Forman RTT (1993) Landscape graphs-ecological modeling with graph-theory to detect configurations common to diverse landscapes. Landsc Ecol 8:239-255

Cartar RV, Real LA (1997) Habitat structure and animal movement: the behaviour of bumble bees in uniform and random spatial resource distributions. Oecologia 112:430-434

Chen S, White BJ, Sanderson MW, Amrine DE, Ilany A, Lanzas C (2014) Highly dynamic animal contact network and implications on disease transmission. Sci Rep 4:4472

Cheney DL, Seyfarth RM (1999) Recognition of other individuals' social relationships by female baboons. Anim Behav 58:67-75

Clutton-Brock TH, Harvey PH (1977) Primate ecology and social organization. J Zool 183:1-39 
Coulon A, Morellet N, Goulard M, Cargnelutti B, Angibault JM, Hewison AJM (2008) Inferring the effects of landscape structure on roe deer (Capreolus capreolus) movements using a step selection function. Landsc Ecol 23:603-614

Couzin ID, Krause J, Franks NR, Levin SA (2005) Effective leadership and decision-making in animal groups on the move. Nature 433: 513-516

Cramp S, Simmons KEL (eds) (1977) Handbook of the birds of Europe, the Middle East and North Africa: the birds of the Western Palearctic. Vol. 1: ostrich to ducks. Oxford University Press, Oxford

Crist TO, Guertin DS, Wiens JA, Milne BT (1992) Animal movement in heterogeneous landscapes - an experiment with Eleodes beetles in shortgrass prairie. Funct Ecol 6:536-544

Croft DP, James R, Ward AJ, Botham MS, Mawdsley D, Krause J (2005) Assortative interactions and social networks in fish. Oecologia 143: 211-219

Croft DP, Madden JR, Franks DW, James R (2011) Hypothesis testing in animal social networks. Trends Ecol Evol 26:502-507

Csardi G, Nepusz T (2006) The igraph software package for complex network research. InterJournal Complex Systems:1695, http:// igraph.org. Accessed 20 May 2018

Dahl J, Greenberg L (1996) Effects of habitat structure on habitat use by Gammarus pulex in artificial streams. Freshw Biol 36:487-495

Dale MRT, Fortin MJ (2010) From graphs to spatial graphs. Annu Rev Ecol Evol S 41:21-38

Donaldson-Matasci MC, Dornhaus A (2012) How habitat affects the benefits of communication in collectively foraging honey bees. Behav Ecol Sociobiol 66:583-592

Eames KTD (2008) Modelling disease spread through random and regular contacts in clustered populations. Theor Popul Biol 73:104-111

Emlen ST, Oring LW (1977) Ecology, sexual selection, and the evolution of mating systems. Science 197:215-223

Fahrig L (2007) Non-optimal animal movement in human-altered landscapes. Funct Ecol 21:1003-1015

Farine DR (2014) Measuring phenotypic assortment in animal social networks: weighted associations are more robust than binary edges. Anim Behav 89:141-153

Farine DR (2015) Proximity as a proxy for interactions: issues of scale in social network analysis. Anim Behav 104:E1-E5

Farine DR (2017) A guide to null models for animal social network analysis. Methods Ecol Evol 8:1309-1320

Farine DR, Firth JA, Aplin LM, Crates RA, Culina A, Garroway CJ, Hinde CA, Kidd LR, Milligan ND, Psorakis I, Radersma R, Verhelst B, Voelkl B, Sheldon BC (2015) The role of social and ecological processes in structuring animal populations: a case study from automated tracking of wild birds. Roy Soc Open Sci 2:150057

Farine DR, Sheldon BC (2015) Selection for territory acquisition is modulated by social network structure in a wild songbird. J Evol Biol 28: 547-556

Farine DR, Sheldon BC (2016) Social ecology of a woodland songbird community: from individual movements to the emergence of population social structure. bioRxiv. doi: https://doi.org/10.1101/085944

Farine DR, Strandburg-Peshkin A, Berger-Wolf T, Ziebart B, Brugere I, Li J, Crofoot MC (2016) Both nearest neighbours and long-term affiliates predict individual locations during collective movement in wild baboons. Sci Rep 6:27704

Farine DR, Strandburg-Peshkin A, Couzin ID, Berger-Wolf TY, Crofoot MC (2017) Individual variation in local interaction rules can explain emergent patterns of spatial organization in wild baboons. Proc R Soc B 284:20162243

Farine DR, Whitehead H (2015) Constructing, conducting and interpreting animal social network analysis. J Anim Ecol 84:1144 1163

Fayet AL, Tobias JA, Hintzen RE, Seddon N (2014) Immigration and dispersal are key determinants of cultural diversity in a songbird population. Behav Ecol 25:744-753
Firth JA, Sheldon BC, Brent LJN (2017) Indirectly connected: simple social differences can explain the causes and apparent consequences of complex social network positions. Proc R Soc B 284:20171939

Firth JA, Sheldon BC, Farine DR (2016) Pathways of information transmission among wild songbirds follow experimentally imposed changes in social foraging structure. Biol Lett 12:20160144

Flack A, Fiedler W, Blas J, Pokrovsky I, Kaatz M, Mitropolsky M, Aghababyan K, Fakriadis I, Makrigianni E, Jerzak L, Azafzaf H, Feltrup-Azafzaf C, Rotics S, Mokotjomela TM, Nathan R, Wikelski M (2016) Costs of migratory decisions: a comparison across eight white stork populations. Sci Adv 2:e1500931

Formica VA, McGlothlin JW, Wood CW, Augat ME, Butterfield RE, Barnard ME, Brodie ED 3rd (2011) Phenotypic assortment mediates the effect of social selection in a wild beetle population. Evolution 65:2771-2281

Formica VA, Wood CW, Larsen WB, Butterfield RE, Augat ME, Hougen HY, Brodie ED 3rd (2012) Fitness consequences of social network position in a wild population of forked fungus beetles (Bolitotherus cornutus). J Evol Biol 25:130-137

Fortin MJ, James PMA, MacKenzie A, Melles SJ, Rayfield B (2012) Spatial statistics, spatial regression, and graph theory in ecology. Spat Stat 1:100-109

Garant D, Kruuk LEB, Wilkin TA, McCleery RH, Sheldon BC (2005) Evolution driven by differential dispersal within a wild bird population. Nature 433:60-65

Getz LL (1961) Home ranges, territoriality, and movement of the meadow vole. J Mammal 42:24-36

Gill FB, Wolf LL (1975) Economics of feeding territoriality in the goldenwinged sunbird. Ecology 56:333-345

Grant EHC, Lowe WH, Fagan WF (2007) Living in the branches: population dynamics and ecological processes in dendritic networks. Ecol Lett 10:165-175

Haddad NM (1999) Corridor and distance effects on interpatch movements: a landscape experiment with butterflies. Ecol Appl 9:612622

Herbert-Read JE, Rosen E, Szorkovszky A et al (2017) How predation shapes the social interaction rules of shoaling fish. Proc R Soc B 284:20171126

Hinde RA (1976) Interactions, relationships and social structure. Man 11: $1-17$

Hoare DJ, Krause J, Peuhkuri N, Godin JGJ (2000) Body size and shoaling in fish. J Fish Biol 57:1351-1366

Ibarra-Macias A, Robinson W, Gaines M (2011) Forest corridors facilitate movement of tropical forest birds after experimental translocations in a fragmented Neotropical landscape in Mexico. J Trop Ecol 27: $547-556$

Jacoby DMP, Brooks EJ, Croft DP, Sims DW (2012) Developing a deeper understanding of animal movements and spatial dynamics through novel application of network analyses. Methods Ecol Evol 3:574583

Jacoby DMP, Fear LN, Sims DW, Croft DP (2014) Shark personalities? Repeatability of social network traits in a widely distributed predatory fish. Behav Ecol Sociobiol 68:1995-2003

Jacoby DMP, Freeman R (2016) Emerging network-based tools in movement ecology. Trends Ecol Evol 31:301-314

Jolles JW, Boogert NJ, Sridhar VH, Couzin ID, Manica A (2017) Consistent individual differences drive collective behavior and group functioning of schooling fish. Curr Biol 27:2862-2868

Jones TB, Aplin LM, Devost I, Morand-Ferron J (2017) Individual and ecological determinants of social information transmission in the wild. Anim Behav 129:93-101

Jonsen ID, Taylor PD (2000) Fine-scale movement behaviors of calopterygid damselflies are influenced by landscape structure: an experimental manipulation. Oikos 88:553-562

Kao A, Berdahl A, Flack A, Westley P, Codling E, Couzin I, Dell A, Biro D (2018) Collective animal navigation and migratory culture: from 
theoretical models to empirical evidence. Phil Trans R Soc B 373: 20170009

Kappeler PM (2019) A framework for studying social complexity. Behav Ecol Sociobiol, https://doi.org/10.1007/s00265-018-2601-8 this issue

Kappeler PM, Barrett L, Blumstein DT, Clutton-Brock TH (2013) Constraints and flexibility in mammalian social behaviour: introduction and synthesis. Phil Trans R Soc B 368:20120337

Kappeler PM, van Schaik CP (2002) Evolution of primate social systems. Int J Primatol 23:707-740

Kays R, Crofoot MC, Jetz W, Wikelski M (2015) Terrestrial animal tracking as an eye on life and planet. Science 348:aaa2478

Kie JG, Ager AA, Bowyer RT (2005) Landscape-level movements of North American elk (Cervus elaphus): effects of habitat patch structure and topography. Landsc Ecol 20:289-300

Kivelä M, Arenas A, Barthelemy M, Gleeson JP, Moreno Y, Porter MA (2014) Multilayer networks. J Complex Networks 2:203-271

Koenig A (2002) Competition for resources and its behavioral consequences among female primates. Int J Primatol 23:759-783

Krause J, Butlin RK, Peuhkuri N, Pritchard VL (2000) The social organization of fish shoals: a test of the predictive power of laboratory experiments for the field. Biol Rev 75:477-501

Krause J, James R, Franks DW, Croft DPE (2015) Animal social networks. Oxford University Press, New York

Krause J, Ruxton GD (2002) Living in groups. Oxford University Press, Oxford

Kurvers RHJM, Krause J, Croft DP, Wilson ADM, Wolf M (2014) The evolutionary and ecological consequences of animal social networks: emerging issues. Trends Ecol Evol 29:326-335

Lantz SM, Karubian J (2017) Environmental disturbance increases social connectivity in a passerine bird. PLoS One 12:e183144

Lattanzio MS, Miles DB (2014) Ecological divergence among colour morphs mediated by changes in spatial network structure associated with disturbance. J Anim Ecol 83:1490-1500

Leshem Y, Yom-Tov Y (1998) Routes of migrating soaring birds. Ibis 140:41-52

Leu ST, Farine DR, Wey TW, Sih A, Bull CM (2016) Environment modulates population social structure: experimental evidence from replicated social networks of wild lizards. Anim Behav 111:23-31

Lurzel S, Kaiser S, Sachser N (2010) Social interaction, testosterone, and stress responsiveness during adolescence. Physiol Behav 99:40-46

Macpherson E, Duarte CM (1991) Bathymetric trends in demersal fish size: is there a general relationship? Mar Ecol-Prog Ser 71:103-112

Maldonado-Chaparro AA, Montiglio PO, Forstmeier W, Kempenaers B, Farine DR (2018) Linking the fine-scale social environment to mating decisions: a future direction for the study of extra-pair paternity. Biol Rev (published online), doi:https://doi.org/10.1111/brv.12408)

Manderson JP, Pessutti J, Hilbert JG, Juanes F (2004) Shallow water predation risk for a juvenile flatfish (winter flounder; Pseudopleuronectes americanus, Walbaum) in a northwest Atlantic estuary. J Exp Mar Biol Ecol 304:137-157

Mansergh IM, Scotts DJ (1989) Habitat continuity and social organization of the mountain pygmy-possum restored by tunnel. J Wildlife Manage 53:701-707

McCoy ED, Bell SS (1991) Habitat structure: the evolution and diversification of a complex topic. In: Bell SS, McCoy ED, Mushinsky HR (eds) Habitat structure. Population and community biology series, vol. 8. Springer, Dordrecht, pp 3-27

McDonald GC, Farine DR, Foster KR, Biernaskie JM (2017) Assortment and the analysis of natural selection on social traits. Evolution 71: 2693-2702

McDonald GC, Pizzari T (2018) Structure of sexual networks determines the operation of sexual selection. P Natl Acad Sci USA 115:E53E61
McIntyre N, Wiens J (1999) How does habitat patch size affect animal movement? An experiment with darkling beetles. Ecology 80:22612270

McLean KA, Trainor AM, Asner GP, Crofoot MC, Hopkins ME, Campbell CJ, Martin RE, Knapp DE, Jansen PA (2016) Movement patterns of three arboreal primates in a Neotropical moist forest explained by LiDAR-estimated canopy structure. Landsc Ecol 31:1849-1862

McNab BK (1963) Bioenergetics and the determination of home range size. Am Nat 97:133-140

Mitani JC, Rodman PS (1979) Territoriality: the relation of ranging pattern and home range size to defendability, with an analysis of territoriality among primate species. Behav Ecol Sociobiol 5:241-251

Mitchell CL, Boinski S, van Schaik CP (1991) Competitive regimes and female bonding in two species of squirrel monkeys (Saimiri oerstedi and S. sciureus). Behav Ecol Sociobiol 28:55-60

Mokross K, Ryder TB, Cortes MC, Wolfe JD, Stouffer PC (2014) Decay of interspecific avian flock networks along a disturbance gradient in Amazonia. Proc R Soc B 281:20132599

Montiglio PO, Gotanda KM, Kratochwil CF, Laskowski KL, Nadell CD, Farine DR (2018a) Nested interaction networks represent a missing link in the study of behavioural and community ecology arXiv. $1804.00927 \mathrm{v} 1$

Montiglio PO, McGlothlin JW, Farine DR (2018b) Social structure modulates the evolutionary consequences of social plasticity: a social network perspective on interacting phenotypes. Ecol Evol 8:14511464

Mourier J, Vercelloni J, Planes S (2012) Evidence of social communities in a spatially structured network of a free-ranging shark species. Anim Behav 83:389-401

Mueller T, O'Hara RB, Converse SJ, Urbanek RP, Fagan WF (2013) Social learning of migratory performance. Science 341:999-1002

Oh KP, Badyaev AV (2010) Structure of social networks in a passerine bird: consequences for sexual selection and the evolution of mating strategies. Am Nat 176:E80-E89

Pasquaretta C, Jeanson R, Andalo C, Chittka L, Lihoreau M (2017) Analysing plant-pollinator interactions with spatial movement networks. Ecol Entomol 42:4-17

Petren K, Case TJ (1998) Habitat structure determines competition intensity and invasion success in gecko lizards. P Natl Acad Sci USA 95: 11739-11744

Pilosof S, Porter MA, Pascual M, Kefi S (2017) The multilayer nature of ecological networks. Nat Ecol Evol 1:0101

Pinter-Wollman N (2015) Nest architecture shapes the collective behaviour of harvester ants. Biol Lett 11:20150695

Pinter-Wollman N, Fiore SM, Theraulaz G (2017) The impact of architecture on collective behaviour. Nat Ecol Evol 1:0111

Proulx SR, Promislow DEL, Phillips PC (2005) Network thinking in ecology and evolution. Trends Ecol Evol 20:345-353

Radersma R, Garroway CJ, Santure AW, de Cauwer I, Farine DR, Slate J, Sheldon BC (2017) Social and spatial effects on genetic variation between foraging flocks in a wild bird population. Mol Ecol 26: 5807-5819

Rezucha R, Reichard M (2014) The effect of social environment on alternative mating tactics in male Endler's guppy, Poecilia wingei. Anim Behav 88:195-202

Rhodes M, Wardell-Johnson GW, Rhodes MP, Raymond B (2006) Applying network analysis to the conservation of habitat trees in urban environments: a case study from Brisbane, Australia. Conserv Biol 20:861-870

Rondinini C, Doncaster CP (2002) Roads as barriers to movement for hedgehogs. Funct Ecol 16:504-509

Ryder TB, McDonald DB, Blake JG, Parker PG, Loiselle BA (2008) Social networks in the lek-mating wire-tailed manakin (Pipra filicauda). Proc R Soc Lond B 275:1367-1374 
Ryder TB, Parker PG, Blake JG, Loiselle BA (2009) It takes two to tango: reproductive skew and social correlates of male mating success in a lek-breeding bird. Proc R Soc Lond B 276:2377-2384

Sachser N, Hennessy MB, Kaiser S (2011) Adaptive modulation of behavioural profiles by social stress during early phases of life and adolescence. Neurosci Biobehav R 35:1518-1533

Schick RS, Loarie SR, Colchero F, Best BD, Boustany A, Conde DA, Halpin PN, Joppa LN, McClellan CM, Clark JS (2008) Understanding movement data and movement processes: current and emerging directions. Ecol Lett 11:1338-1350

Shepard DB, Kuhns AR, Dreslik MJ, Phillips CA (2008) Roads as barriers to animal movement in fragmented landscapes. Anim Conserv 11:288-296

Shepard ELC, Williamson C, Windsor SP (2016) Fine-scale flight strategies of gulls in urban airflows indicate risk and reward in city living. Phil Trans R Soc B 371:20150394

Shizuka D, Farine DR (2016) Measuring the robustness of network community structure using assortativity. Anim Behav 112:237-246

Sih A, Spiegel O, Godfrey S, Leu S, Bull CM (2018) Integrating social networks, animal personalities, movement ecology and parasites: a framework with examples from a lizard. Anim Behav 136:195-205

Silk JB, Alberts SC, Altmann J (2003) Social bonds of female baboons enhance infant survival. Science 302:1231-1234

Silk JB, Beehner JC, Bergman TJ, Crockford C, Engh AL, Moscovice LR, Wittig RM, Seyfarth RM, Cheney DL (2009) The benefits of social capital: close social bonds among female baboons enhance offspring survival. Proc R Soc Lond B 276:3099-3104

Silk MJ, Croft DP, Delahay RJ, Hodgson DJ, Boots M, Weber N, McDonald RA (2017a) Using social network measures in wildlife disease ecology, epidemiology, and management. Bioscience 67: 245-257

Silk MJ, Weber N, Steward LC, Delahay RJ, Croft DP, Hodgson DJ, Boots M, McDonald RA (2017b) Seasonal variation in daily patterns of social contacts in the European badger Meles meles. Ecol Evol 7:9006-9015

Slabbekoorn H, Smith TB (2002) Bird song, ecology and speciation. Phil Trans R Soc B 357:493-503

Slagsvold T, Wiebe KL (2018) Immigrants and locally recruited birds differ in prey delivered to their offspring in blue tits and great tits. Anim Behav 139:127-135

Sosa S (2016) The influence of gender, age, matriline and hierarchical rank on individual social position, role and interactional patterns in Macaca sylvanus at 'La Forêt des Singes': a multilevel social network approach. Front Psychol 7:529

Spiegel O, Leu ST, Bull CM, Sih A (2017) What's your move? Movement as a link between personality and spatial dynamics in animal populations. Ecol Lett 20:3-18

Spiegel O, Leu ST, Sih A, Bull CM (2016) Socially interacting or indifferent neighbours? Randomization of movement paths to tease apart social preference and spatial constraints. Methods Ecol Evol 7:971-979
Spiegel O, Sih A, Leu ST, Bull CM (2018) Where should we meet? Mapping social network interactions of sleepy lizards shows sexdependent social network structure. Anim Behav 136:207-215

Sterck EHM, Watts DP, van Schaik CP (1997) The evolution of female social relationships in nonhuman primates. Behav Ecol Sociobiol 41:291-309

Strandburg-Peshkin A, Farine DR, Crofoot MC, Couzin ID (2017) Habitat and social factors shape individual decisions and emergent group structure during baboon collective movement. Elife 6:e19505

Tucker MA, Bohning-Gaese K, Fagan WF et al (2018) Moving in the Anthropocene: global reductions in terrestrial mammalian movements. Science 359:466-469

VanderWaal KL, Atwill ER, Isbell LA, McCowan B (2014) Linking social and pathogen transmission networks using microbial genetics in giraffe (Giraffa camelopardalis). J Anim Ecol 83:406-414

Vasudev D, Fletcher RJ, Goswami VR, Krishnadas M (2015) From dispersal constraints to landscape connectivity: lessons from species distribution modeling. Ecography 38:967-978

Webster MM, Atton N, Hoppitt WJE, Laland KN (2013) Environmental complexity influences association network structure and networkbased diffusion of foraging information in fish shoals. Am Nat 181: 235-244

Weiss NM, Franks WD, Croft PD, Whitehead H (2019) Measuring social complexity from association data using mixture models. Behav Ecol Sociobiol, https://doi.org/10.1007/s00265-018-2603-6 this issue

Whitehead H (1997) Analysing animal social structure. Anim Behav 53: 1053-1067

Whitehead H (2008) Analyzing animal societies: quantitative methods for vertebrate social analysis. University of Chicago Press, Chicago

Whitehead H, James R (2015) Generalized affiliation indices extract affiliations from social network data. Methods Ecol Evol 6:836-844

Wilkinson SG, Carter GG, Bohn MK et al (2019) Kinship, association and social complexity in bats. Behav Ecol Sociobiol, https://doi.org/ $10.1007 / \mathrm{s} 00265-018-2608-1$ this issue

Wittemyer G, Douglas-Hamilton I, Getz WM (2005) The socioecology of elephants: analysis of the processes creating multitiered social structures. Anim Behav 69:1357-1371

Wolf JBW, Mawdsley D, Trillmich F, James R (2007) Social structure in a colonial mammal: unravelling hidden structural layers and their foundations by network analysis. Anim Behav 74:1293-1302

Wolf JBW, Trillmich F (2008) Kin in space: social viscosity in a spatially and genetically substructured network. Proc R Soc Lond B 275: 2063-2069

Wolf TE, Ngonga Ngomo AC, Bennett NC, Burroughs R, Ganswindt A (2018) Seasonal changes in social networks of giraffes. J Zool (published online), doi:https://doi.org/10.1111/jzo.12531)

Yang WJ, Maldonado-Chaparro AA, Blumstein DT (2017) A cost of being amicable in a hibernating mammal. Behav Ecol 28:11-19 